\title{
2-Methoxyestradiol Reverses the Pro-Carcinogenic Effect of L-Lactate in Osteosarcoma 143B Cells
}

\author{
MAGDALENA GORSKA-PONIKOWSKA ${ }^{1,2}$, ALICJA KUBAN-JANKOWSKA ${ }^{1}$, \\ AGNIESZKA DACA ${ }^{3}$ and STEPHAN NUSSBERGER ${ }^{2}$ \\ ${ }^{1}$ Department of Medical Chemistry, Medical University of Gdansk, Gdansk, Poland; \\ ${ }^{2}$ Department of Biophysics, Institute of Biomaterials and Biomolecular Systems, \\ University of Stuttgart, Stuttgart, Germany; \\ ${ }^{3}$ Department of Pathology and Experimental Rheumatology, Medical University of Gdansk, Gdansk, Poland
}

\begin{abstract}
Background/Aim: According to the reverse Warburg effect, tumor cells may metabolize lactate as an energy source and shuttle L-lactate to neighboring cancer cells, adjacent stroma, and vascular endothelial cells, thus inducing metabolic reprogramming. An increased tumor L-lactate level strictly correlates with increased metastasis, tumor recurrence and a poor outcome. A potent anticancer agent that may act on L-lactate activated cells is 2-metoxyestradiol. Thus, the aim of the study was to evaluate whether a potent anticancer agent, 2-methoxyestradiol, is able to reverse L-lactate-induced metabolic reprogramming in osteosarcoma 143B cells. Materials and Methods: We used flow cytometry in order to determine cell death, autophagy, expression of KI-67, mitochondrial membrane depolarization. We performed cell proliferation assay in order to determine cell viability and cell migration assay to determine invasive potential of osteosarcoma cells. While, CalcuSyn software was used in order to evaluate the interaction between 2-methoxyestradiol and L-lactate. Results: We demonstrated that 2-methoxyestradiol abolished L-lactate-induced migration and proliferation of osteosarcoma cells. Moreover, we observed that this effect was associated with regulation of Ki-67 and induction of autophagy. Conclusion: 2Methoxyestradiol is a potent anticancer agent also under metabolic reprogramming conditions.
\end{abstract}

This article is freely accessible online.

Correspondence to: Magdalena Gorska-Ponikowska (MGP), Debinki 1 Street, 80-211 Gdansk, Poland. Tel: +48 583491450, Fax: +48 583491456, e-mail: m.gorska@gumed.edu.pl

Key Words: 2-Methoxyestradiol, L-lactate, osteosarcoma, tumor microenvironment.
Cancer cells are traditionally characterized by increased glucose uptake, high rates of aerobic glycolysis, increased lactic acid production, impaired mitochondrial function and decreased extracellular $\mathrm{pH}$. These characteristics are known as the 'Warburg effect' (1-3). The 'Warburg effect' is also observed in cancer-associated fibroblasts and mesenchymal stem cells (1-11), which secrete lactate and ketones into the microenvironment of the tumor. Lactic acid exists as L- and D- optical isomers. In mammals including humans, lactate is present almost entirely as L-lactate $(12,13)$. Interestingly, a variety of human cancer cell lines and human tumors, including breast, prostate, head, neck, and osteosarcoma cancers, import these metabolites and deliver them to the mitochondrial TCA cycle, thereby promoting ATP generation and cell proliferation (1-14). According to this 'reverse Warburg effect', tumor cells can induce metabolic reprogramming by shuttling lactate as an energy source to neighboring cancer cells, to the adjacent stroma and to vascular endothelial cells $(1,14)$.

Tumors contain both aerobic and hypoxic regions that form a metabolic symbiosis that is crucial for tumor cell survival $(15,16)$. The cancer cells located in the hypoxic regions export lactate, which acidifies the tumor environment; the cells located in the aerobic regions, however, import lactate and utilize it for oxidative phosphorylation (4). Bonuccelli and colleagues (2) suggested that L-lactate metabolism in cancer cells may explain why diabetic patients have an increased risk of cancer development and a tendency towards autophagy/mitophagy in their adipose tissue. An increased tumor L-lactate level strictly correlates with increased metastasis, tumor recurrence and poor outcome (6-9).

L-lactate metabolism and the reverse Warburg effect has been clearly established in osteosarcoma cells. It has been demonstrated that the secretion of lactate and ketones by the mesenchymal stem cells drives mitochondrial biogenesis and increases the mitochondrial activity in osteosarcoma cells (1, 
3). Mesenchymal stem cells have been demonstrated to feed the osteosarcoma cells by producing and secreting L-lactate $(1,3)$. Co-culture of osteosarcoma cells with mesenchymal stem cells increased the aggressive potential of tumor cells due to the generation of oxidative stress (1).

Here, we set out to determine the anticancer potential of 2-methoxyestradiol (2-ME) (17-30), a natural derivative of $17 \beta$-estradiol, in L-lactate-activated osteosarcoma cells. Under the brand name Panzem, 2-ME is currently being evaluated in preclinical studies and for the clinical treatment of numerous types of malignancies including breast, prostate cancer, or osteosarcoma (17-30). Recently, we showed that 2-ME stimulates the nuclear recruitment of neuronal nitric oxide synthase (nNOS) and cellular nitric oxide (NO) generation, which induces DNA damage and cancer cell death (19). We have also determined that 2-ME reverses the metabolic reprogramming that is induced by low concentrations of D-serine and glycine (17).

We demonstrated that 2-ME abolished the L-lactateinduced migration and proliferation of osteosarcoma cells. Both effects were correlated with low Ki-67 levels and high autophagy activities. Moreover, 2-ME effectively induced cell death in L-lactate-activated cells, which also indicated a potent anticancer activity under metabolic reprogramming conditions. Our data indicate that 2-ME acts both directly and indirectly on tumor cells by inducing tumor cell death through effects on the tumor microenvironment.

\section{Materials and Methods}

Reagents. 2-methoxyestradiol (No. M6383), L(+)Lactic acid sodium (L7022), the osteosarcoma 143B cell line (No. 91112502), tissue culture media, penicillin streptomycin solution, and fetal bovine sera were obtained from Sigma Aldrich (Warsaw, Poland). The Muse Autophagy LC3-antibody based kit, Ki-67 Proliferation Kit, and Cell Viability Assay were purchased from Merck (Warsaw, Poland).

Cell culture. The $143 \mathrm{~B}$ osteosarcoma cells were cultured at $37^{\circ} \mathrm{C}$ in a humidified atmosphere with $5 \% \quad \mathrm{CO}_{2}$. The EMEM (EBSS) medium was supplemented with $2 \mathrm{mM}$ glutamine, $1 \%$ NonEssential Amino Acids (NEAA), and 10\% heat-inactivated Fetal Bovine Serum (FBS).

Cell treatment. To evaluate the effect of lactate on tumor, all the analyses were performed using sodium L-lactate (indicated in the text as L-lactate). This is the sodium salt of $\mathrm{L}(+)$-acid lactic, which preserve lactate activity without affecting the $\mathrm{pH}$ of media. 143B cells were treated with 2-ME separately and in combination with $\mathrm{L}$ lactate. Initially, the cells were treated for $24 \mathrm{~h}$ with $10 \mathrm{mM} \mathrm{L}$ lactate to induce the reverse Warburg effect (1-3). After this, the medium was changed to those containing L-lactate or L-lactate and 2-ME (Figure 1). Cells treated with 2-ME alone were also used in the study (Figure 1). The treatments were administered according to the experimental design. The treatments were performed in EMEM containing 1\% charcoal-stripped FBS (Sigma Aldrich, Poland). Charcoal-stripped FBS is used to elucidate the effects of

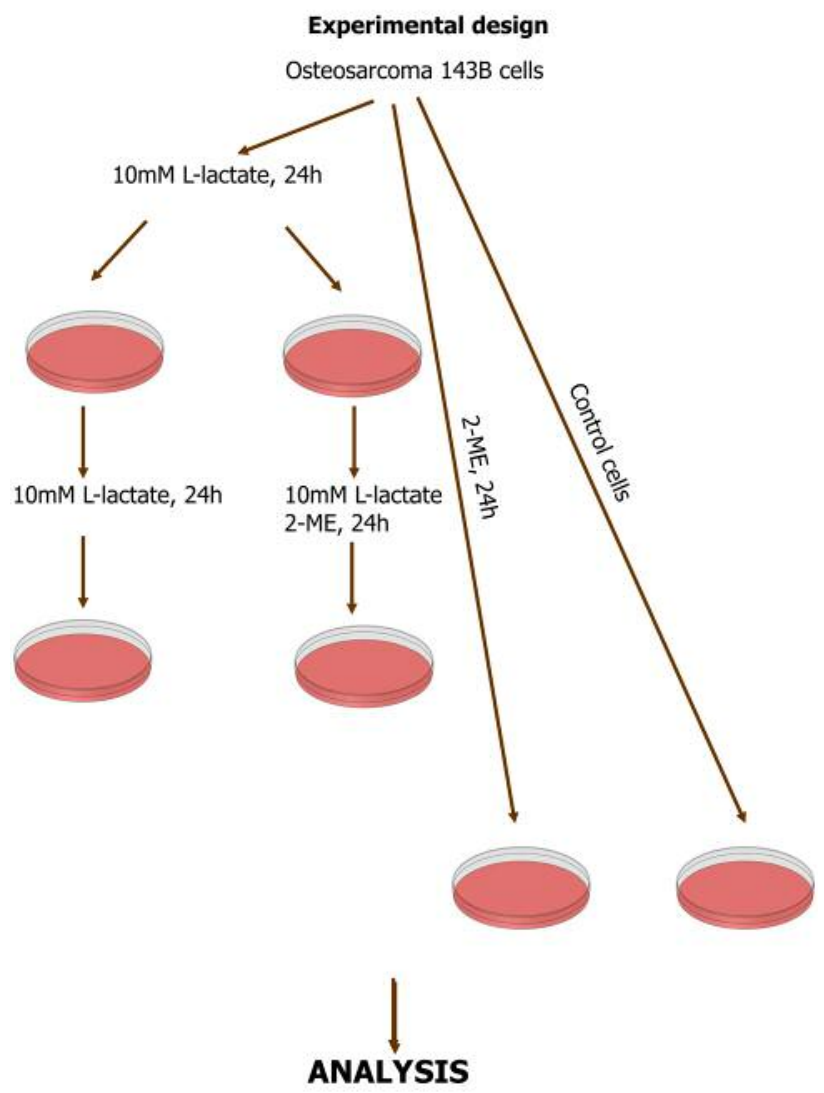

Figure 1. Experimental design. Osteosarcoma $143 B$ cells were first treated with L-lactate to induce the reverse Warburg effect. Afterword, the cells were continuously treated with L-lactate and/or 2-ME. Cells treated separately with 2-ME and control cells were also used.

hormones in various in vitro systems. Pyruvate and Lactate-free EMEM medium was chosen for cell culture and treatment due to its low glucose level, in order to avoid the effects of glucose and the Warburg effect in osteosarcoma cells.

Assessment of cell viability. Osteosarcoma 143B cells were seeded onto six-well plates at a density of $3 \times 10^{5}$ cells per well. After $24 \mathrm{~h}$, the cells were incubated with 2-ME and/or L-lactate according to the experimental design. The cells were then pelleted and incubated with the Muse Count and Viability Reagent according to the manufacturer's protocol (Merck Millipore, Warsaw, Poland) (21). After this, the cells were analyzed $(5,000$ events/sample). The signals were detected using the Muse Cell Analyzer (Merck Millipore, Warsaw, Poland), which is based on flow cytometric technology. The results were then analyzed with the Muse 1.4 analysis software. Each experiment was performed at least three times.

Cell proliferation assay. The proliferation assay was performed as previously described (14). Briefly, osteosarcoma cells were seeded in 96-well plates at a density of 8,000 cells/well. The cells were then treated with L-lactate or 2-ME separately and in combination. 
Twenty microliters of CellTiter 96 AQueous One Solution Reagent was added to each well of the 96-well assay plate containing the samples in $100 \mu \mathrm{l}$ of culture medium. The plates were incubated at $37^{\circ} \mathrm{C}$ for $4 \mathrm{~h}$ in a humidified $5 \% \mathrm{CO}_{2}$ atmosphere. The absorbance was recorded at $490 \mathrm{~nm}$ using a $96-$-well plate reader. The results are presented as the percentage of that of the control cells (untreated cells). Each experiment was performed at least three times.

CalcuSyn software 2.11 (Biosoft). The analysis of interaction between L-lactate and 2-ME was performed as previously described (14) using a general equation for the dose-effect relationship. This equation shows the relationship between the Dose and the Effect in the simplest possible form:

$$
\mathrm{f}_{\mathrm{a}} / \mathrm{f}_{\mathrm{u}}=\left(\mathrm{D} / \mathrm{D}_{\mathrm{m}}\right)^{\mathrm{m}}
$$

where:

D the dose of drug

Dm the median-effect dose signifying the potency (see below)

fa the fraction affected by the dose

$\mathrm{fu}$ the fraction unaffected, where fu=1-fa

$\mathrm{m}$ an exponent signifying the sigmoidicity (shape) of the dose-effect curve (see below)

The median-effect plot: A plot of $x=\log (D)$ vs $y=\log (f a / f u)$.

Dm value: The median-effect dose or concentration. $\log \mathrm{Dm}$ is the $\mathrm{x}$-intercept of the median-effect plot.

$m$ value: A measurement of the sigmoidicity of the dose-effect curve; $\mathrm{m}=1,>1$, and $<1$ indicate hyperbolic, sigmoidal, and negative sigmoidal shapes, respectively. Determined by the slope of the median-effect plot.

$r$ value: The linear correlation coefficient of the median-effect plot. Combination index (CI): A quantitative measure of the degree of drug interaction in terms of additive effect $(\mathrm{CI}=1)$, synergism (CI $<1)$, or antagonism $(\mathrm{CI}>1)$ for a given endpoint of the effect measurement.

Cell migration assay kit (BioVendor). The cell migration chips were coated according to the manufacturer's protocol. Next, the cells were loaded into the pre-filled chips at a density of $9 \times 10^{5} \mathrm{cell} / \mathrm{ml}$ in the appropriate medium containing 2-ME, L-lactate, or the combination. The chips were placed in a humid chamber and incubated at $37^{\circ} \mathrm{C}$ with $5 \% \mathrm{CO}_{2}$. The migration of cells was then observed. The post-migration cell morphology was determined by fixation with $10 \%$ formalin and staining the cells with crystal violet. The migration distances were observed using a phase contrast inverted microscope after $0,6,12,24$, and $48 \mathrm{~h}$ of incubation (magnification $\times 40$, scale bar: $30 \mu \mathrm{m}$ ).

Ki-67 Proliferation assay. Osteosarcoma 143B cells were seeded into 6 -well plates at a density of $3 \times 10^{5}$ cells/dish. After $24 \mathrm{~h}$, the cells were incubated with 2-ME and/or L-lactate according to the experimental design. Afterwards, the cells were fixed, permeabilized and stained with an antibody to Human Ki-67-PE. Afterward, the cells were analyzed (5,000 events/sample), and the signals were detected using the Muse Cell Analyzer (Merck Millipore, Warsaw, Poland). The results were then analyzed with the Muse 1.4 analysis software. Each experiment was performed at least three times.

Mitochondrial membrane depolarization. Osteosarcoma 143B cells were seeded onto $10 \mathrm{~cm}$ culture dishes at a density of $2 \times 10^{6}$ cells/dish. After $24 \mathrm{~h}$, the cells were incubated with 2-ME and/or
L-lactate according to the experimental design. The cells were then pelleted and incubated for 20 min with the Muse ${ }^{\mathrm{TM}}$ MitoPotential Reagent (21) according to manufacturer's protocol. After this, the cells were analyzed (5,000 events/sample), and the signals were detected using the Muse Cell Analyzer (Merck Millipore, Poland). The results were then analyzed with the Muse 1.4 analysis software. Each experiment was performed at least three times.

Autophagy LC3-antibody-based detection. Osteosarcoma 143B cells were seeded onto $10-\mathrm{cm}$ culture dishes at a density of $4 \times 10^{4}$ cells/dish. After $24 \mathrm{~h}$, the cells were incubated with 2-ME and/or L-lactate according to the experimental design. The cells were then pelleted and incubated with antibody detection reagents and stained with Anti-LC3 Alexa Fluor ${ }^{\circledR}$ 555, clone 4E12 according to manufacturer's protocol. Afterward, the cells were analyzed $(5,000$ events/sample), and the signals were detected using the Muse Cell Analyzer (Merck Millipore, Poland). The results were then analyzed with the Muse 1.4 analysis software. Each experiment was performed at least three times.

Induction of cell death. The analysis was performed as previously described (19). Osteosarcoma 143B cells were seeded onto six-well plates at a density of $3 \times 10^{5}$ cells/well. After $24 \mathrm{~h}$, the cells were incubated with 2-ME and/or L-lactate according to the experimental design. The cells were then pelleted and incubated with Annexin V and PI according to manufacturer's protocol (BD Pharmingen, Poland). Afterwards, the cells $\left(3 \times 10^{4} /\right.$ sample) were analyzed, and the fluorescent signals of the Annexin V conjugate and PI were detected at the fluorescence intensity channels FL1 and FL3 (BD FACScan). The results were then analyzed with Cyflogic software, version 1.2.1. Each experiment was performed at least three times.

Statistical analysis. The results represent the means \pm SD from at least three independent experiments. All microscopic evaluations were performed using randomized and coded slides. The differences between the control samples and the 2-ME-treated samples were evaluated using one-way analysis of variance (ANOVA) with post hoc testing with a Dunnett's multiple comparison test or a T test combined with Wilcoxon test. A $p$-value of less than 0.01 was considered to indicate statistical significance. The data were imported and analyzed with GraphPad Prism (GraphPad Software v.6).

\section{Results}

Effect of glucose on treatment with L-lactate. First, to determine whether L-lactate affected the cell viability as a function of low (lg) or high glucose (hg) medium, we observed the impact of a $48 \mathrm{~h}$ treatment with $10 \mathrm{mM} \mathrm{L-}$ lactate on the viability of the osteosarcoma 143B cells (Figure 2A). As shown in this figure, we did not observe any significant difference in the cell viability between treatments with L-lactate in low glucose and high glucose medium. Thus, for the subsequent studies, we used the low glucose medium to limit the Warburg effect in the osteosarcoma cells.

Cytotoxic effects of 2-ME and cytoprotective effect of $L$ lactate on osteosarcoma $143 \mathrm{~B}$ cells. Our next goal was to evaluate impact of treatment with L-lactate alone and in 

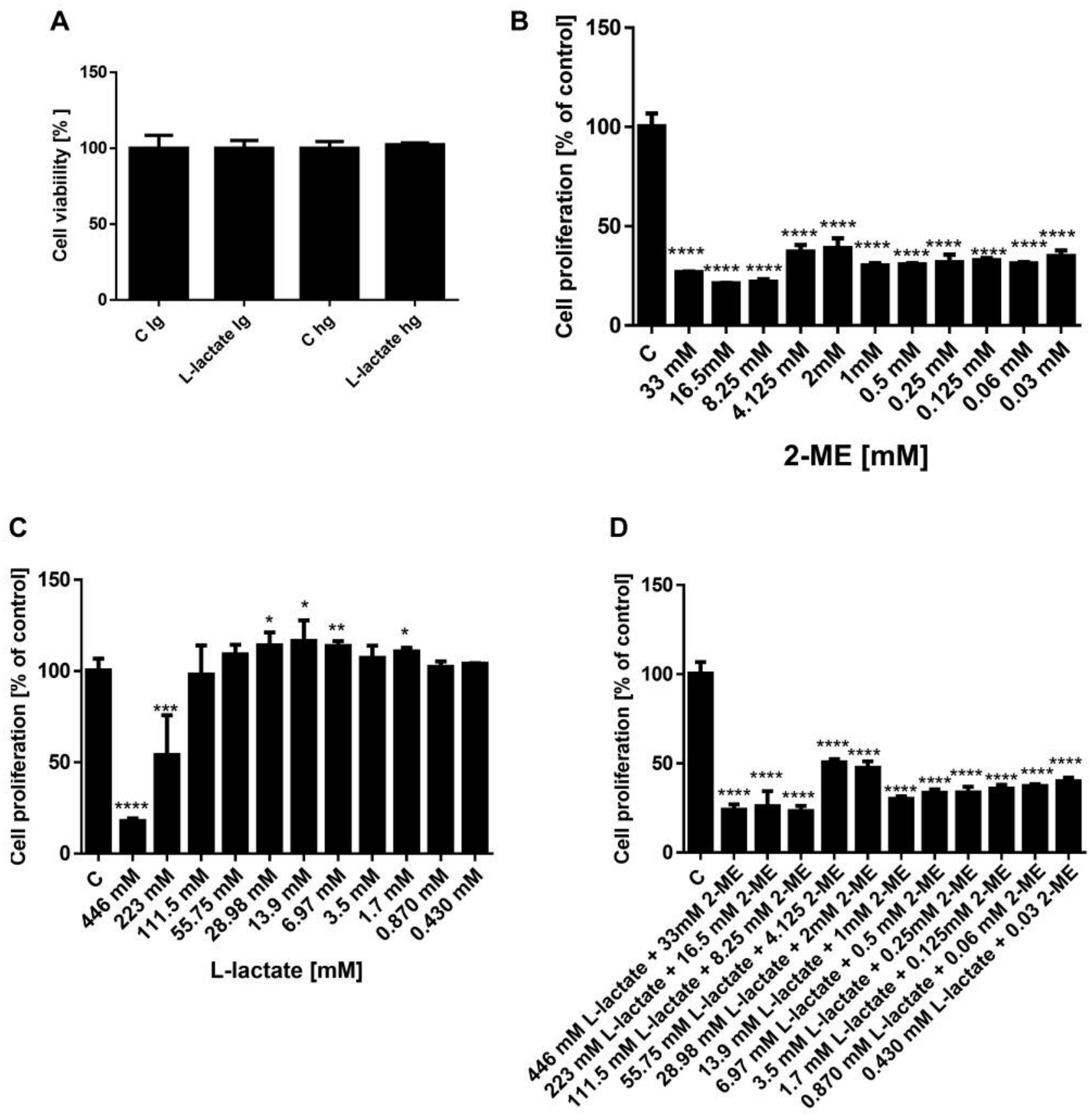

\section{L-lactate + 2-ME [mM]}

Figure 2. Effects of L-lactate in low and high glucose medium on osteosarcoma cell viability (A). Effect of 2-ME, L-lactate and combination on proliferation of osteosarcoma $143 B$ cells $(B-D)$. The inhibition of osteosarcoma proliferation was determined using the MTS assay. The values are the means $\pm S E$ of three independent experiments ( $N=6$ replicate cultures). The absence of an error bar denotes a line thickness greater than the error. $* * p<0.001, * * * p<0.0001, * * * * p<0.00001$ versus control cells $(C)$.

combination with 2-ME on proliferation of osteosarcoma 143B cells using the MTS assay. In our experimental model, the osteosarcoma 143B cells were first treated for $24 \mathrm{~h}$ with various concentrations of L-lactate to increase the metastatic potential of cells $(1,2)$. Then, to observe the anticancer effect of 2-ME, the media were changed to those containing L-lactate, or L-lactate and 2-ME at various concentrations, and the cells were incubated for $24 \mathrm{~h}$ longer. In addition, 

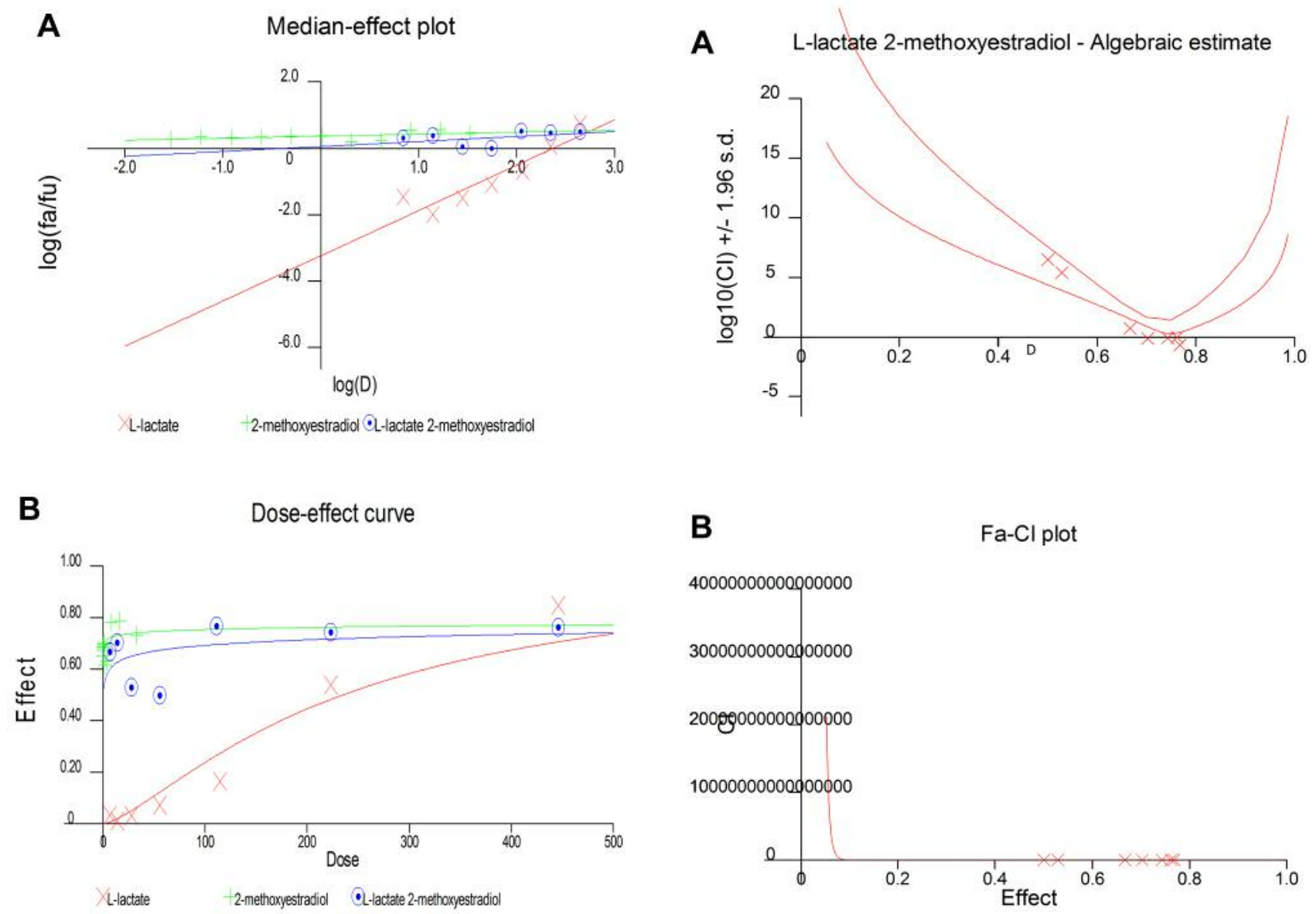

Figure 3. Antagonistic effects between L-lactate and 2-ME. The data obtained from the MTS assay were analyzed using CalcuSyn software version 2.0 (Biosoft) and presented in the form of a Median-Effect Plot (A) and a Dose-Effect curve (B).

cells were treated with 2-ME alone for $24 \mathrm{~h}$. The cytotoxicity was then determined, and the $\mathrm{EC}_{50}$ was calculated using CalcuSyn software (Figures 3 and 4).

Consistent with our previously published results (18-20), the $\mathrm{EC}_{50}$ for 2-ME was determined to be in the range of $1.29 \times 10^{-6} \mathrm{M}$ (Figure 2B). As shown in Figure 2C, L-lactate at the high concentrations of $446 \mathrm{mM}$ and $223 \mathrm{mM}$ decreased the osteosarcoma cell viability with a calculated $\mathrm{EC}_{50}$ value equal to $224.4 \mathrm{mM}$. In contrast, lower concentrations of L-lactate in the range of $29 \mathrm{mM}$ to $1.7 \mathrm{mM}$ resulted in pro-proliferative effects of the compound (Figure 2B). Importantly, 2-ME abrogated the pro-carcinogenic effect of L-lactate (Figure 2D). On the basis of these results and literature data $(1,2)$, for the next studies we selected $10 \mathrm{mM}$ L-lactate and a high pharmacological concentration of 2-ME: $10 \mu \mathrm{M}$.

B

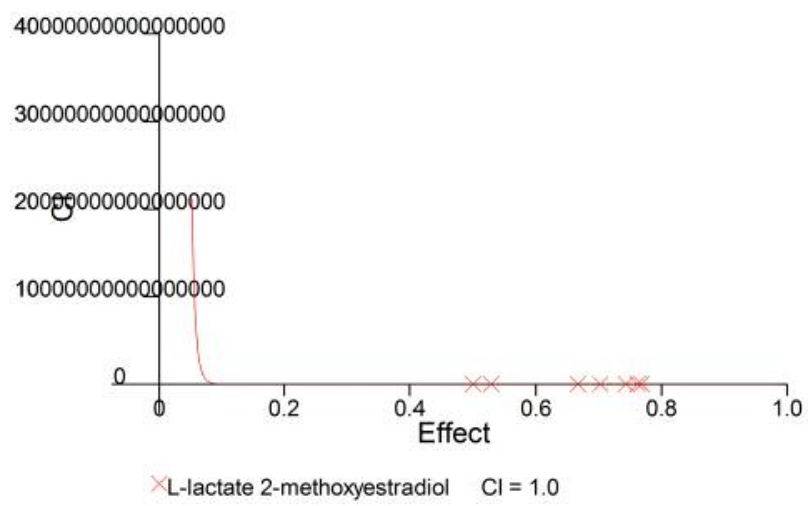

Figure 4. Antagonistic effects between L-lactate and 2-ME. The data obtained from the MTS assay were analyzed using CalcuSyn software version 2.0 (Biosoft) and presented in the form of an algebraic estimate (fractional effect) (A), and a Fa-CI plot (B).

Antagonistic effect between 2-ME and L-lactate calculated by CalcuSyn Software. Subsequently, we used CalcuSyn software to determine the combination index (CI) and evaluate the interaction between 2-ME and L-lactate (Figures 3 and 4). The interaction between compounds is presented in Figure 3 as a Median-effect plot (A), a Dose-effect curve (B), while in Figure 4, an Algebraic estimate (A), and a FaCI plot (B) (Methods section). The estimated CI value at $\mathrm{EC}_{50}$ was 24344 whereas the CI value at EC75 was 2, which suggested an antagonism between 2-ME and L-lactate (Figures 3 and 4, Table I).

Effect of treatment with 2-ME and/or L-lactate on migration of osteosarcoma $143 \mathrm{~B}$ cells. To determine the migratory potential of osteosarcoma cells that had been treated with $10 \mathrm{mM}$ L-lactate, $10 \mu \mathrm{M} 2-\mathrm{ME}$, or the combination, we 
Table I. Antagonistic effects between 2-ME and L-lactate. The data in Table I include the following parameters: Dm value: The median-effect dose or concentration. It is usually represented by the $E D_{50}$ or $I C_{50} . m$ value: A measurement of the sigmoidicity of the dose-effect curve; $m=1,>1$, and $<1$ indicates hyperbolic, sigmoidal, and negative sigmoidal shapes, respectively. Combination index (CI): A quantitative measure of the degree of drug interaction in terms of additive effect $(C I=1)$, synergism $(C I<1)$, or antagonism $(C I>1)$ for a given endpoint of the effect measurement. The analysis was performed using CalcuSyn Software version 2.11 from Biosoft.

\begin{tabular}{lccccc}
\hline Drug & \multicolumn{3}{c}{ CI Values at } \\
\cline { 2 - 6 } & $\mathrm{ED}_{50}$ & $\mathrm{ED}_{75}$ & $\mathrm{ED}_{90}$ & $\mathrm{Dm}$ & $\mathrm{m}$ \\
\hline L-Lactate (not a combination) & $\mathrm{N} / \mathrm{A}$ & $\mathrm{N} / \mathrm{A}$ & $\mathrm{N} / \mathrm{A}$ & 234,0934 & 1,36496 \\
2-methoxyestradiol (not a combination) & $\mathrm{N} / \mathrm{A}$ & $\mathrm{N} / \mathrm{A}$ & $\mathrm{N} / \mathrm{A}$ & $1,29 \mathrm{E}-06$ & 0,06187 \\
L-lactate + 2-methoxyestradiol & 24344 & 2,00643 & 886,2416 & 0,4242 & 0,14937 \\
\hline
\end{tabular}

performed a cell migration assay. As demonstrated in Figure $5 \mathrm{~A}$, the migration rate of the control cells was determined to be $7.7 \mu \mathrm{m} / \mathrm{h}$. Moreover, we observed a dramatic increase to a migration rate of $18.6 \mu \mathrm{m} / \mathrm{h}$ for osteosarcoma cells after 48 $\mathrm{h}$ of treatment with $10 \mathrm{mM}$ L-lactate (Figure $5 \mathrm{~A}$ ). In contrast, a 48-h treatment with $10 \mu \mathrm{M} 2$-ME reduced the migration rate for the osteosarcoma cells to $1.84 \mu \mathrm{m} / \mathrm{h}$ (Figure 5A). Importantly, the pro-migratory effect of Llactate was significantly reduced to $2.6 \mu \mathrm{m} / \mathrm{h}$ by $10 \mu \mathrm{M} 2-$ ME (Figure 5A).

Impact of 2-ME and/or L-lactate on proliferation and expression of Ki-67 of osteosarcoma $143 \mathrm{~B}$ cells. Because $\mathrm{Ki}$ 67 is an important marker for the efficiency of chemotherapy in osteosarcoma cells $(31,32)$, we next measured the expression of Ki-67 after treatment with 2-ME and L-lactate separately and in combination. As in the previous experiments, in our experimental model osteosarcoma 143B cells were first treated for $24 \mathrm{~h}$ with $10 \mathrm{mM}$ L-lactate to increase the metastatic potential of the cells $(1,2)$. Subsequently, to observe the anticancer effect of 2-ME in L-lactate-activated cells, the medium was changed to those containing $10 \mathrm{mM}$ L-lactate or the combination of $10 \mathrm{mM}$ L-lactate and $10 \mu \mathrm{M} 2-\mathrm{ME}$, and the cells were incubated for $24 \mathrm{~h}$ longer. In addition, cells were treated for $24 \mathrm{~h}$ with $10 \mu \mathrm{M} 2-\mathrm{ME}$ alone. As shown in Figure $5 \mathrm{~B}$, a 24-h treatment with $10 \mu \mathrm{M} 2-\mathrm{ME}$ significantly reduced the $\mathrm{Ki}-67$ expression to $38 \%$ whereas that of the control cells was $75.5 \%$. In contrast, a 48-h treatment with $10 \mathrm{mM}$ L-lactate increased the Ki-67 expression to $89 \%$ (Figure 5B). Notably, the addition of $10 \mu \mathrm{M} 2-\mathrm{ME}$ to the L-lactate-activated cells resulted in a reversal of the L-lactate-induced $\mathrm{Ki}-67$ expression down to $74 \%$ (Figure 5B).

Impact of treatment with 2-ME and/or L-lactate on induction of autophagy based on LC3 expression. Ki-67 expression is associated with LC3 expression especially early in the carcinogenesis process (33). The osteosarcoma cells were treated with $10 \mathrm{mM}$ L-lactate alone for $24 \mathrm{~h}$ and subsequently treated for $24 \mathrm{~h}$ longer with L-lactate or the combination of L-lactate and $10 \mu \mathrm{M}$ 2-ME. In addition, cells were treated for $24 \mathrm{~h}$ with $10 \mu \mathrm{M} 2-\mathrm{ME}$. The cells were stained with the anti-LC3/Alexa Fluor 555-conjugated antibody and analyzed using the Muse Cell Analyzer (Merck Millipore, Warsaw, Poland). The obtained data are presented as the autophagy induction ratio, which was calculated as the ratio between the target sample fluorescence and that of the control sample. As shown in Figure 5C, a 24-h treatment with $10 \mu \mathrm{M} 2-\mathrm{ME}$ resulted in induction of autophagy in $12 \%$ of the cells (Figure 5C). A 48-h treatment with L-lactate resulted in an induction of autophagy in $23 \%$ of the cells (Figure 5C). In contrast, treatment with the combination of the agents did not have a significant impact on the induction of autophagy (Figure 5C).

Impact of treatment with 2-ME and/or L-lactate on mitochondrial membrane depolarization. Because one of the mechanisms for the anticancer activity of 2-ME is the induction of reactive nitrogen species (17-21), we next determined whether treatment with 2-ME and/or L-lactate affected the mitochondrial depolarization and further affected the induction of cell death. As in the previous experiments, the osteosarcoma $143 \mathrm{~B}$ cells were first treated with L-lactate for $24 \mathrm{~h}$, after which the cells were treated for an additional $24 \mathrm{~h}$ with $10 \mu \mathrm{M} 2-\mathrm{ME}$ and/or $10 \mathrm{mM} \mathrm{L-}$ lactate separately and in combination. As shown in Figure $6 \mathrm{~A}$, we observed depolarization of the mitochondrial membrane in $61 \%$ of the cells (Figure 6A) which is consistent with previously published data $(18,21)$. L-lactate used alone slightly changed the mitochondrial membrane potential (19\% of the total cells were depolarized) compared with control cells (9.7\% of total depolarized cells) (Figure 6A). However, after the combined treatment with L-lactate and 2-ME, the mitochondrial membrane depolarization was significantly increased: up to $78 \%$ of the cells were depolarized compared to cells treated with L-lactate or 2ME separately (Figure 6A). 
A
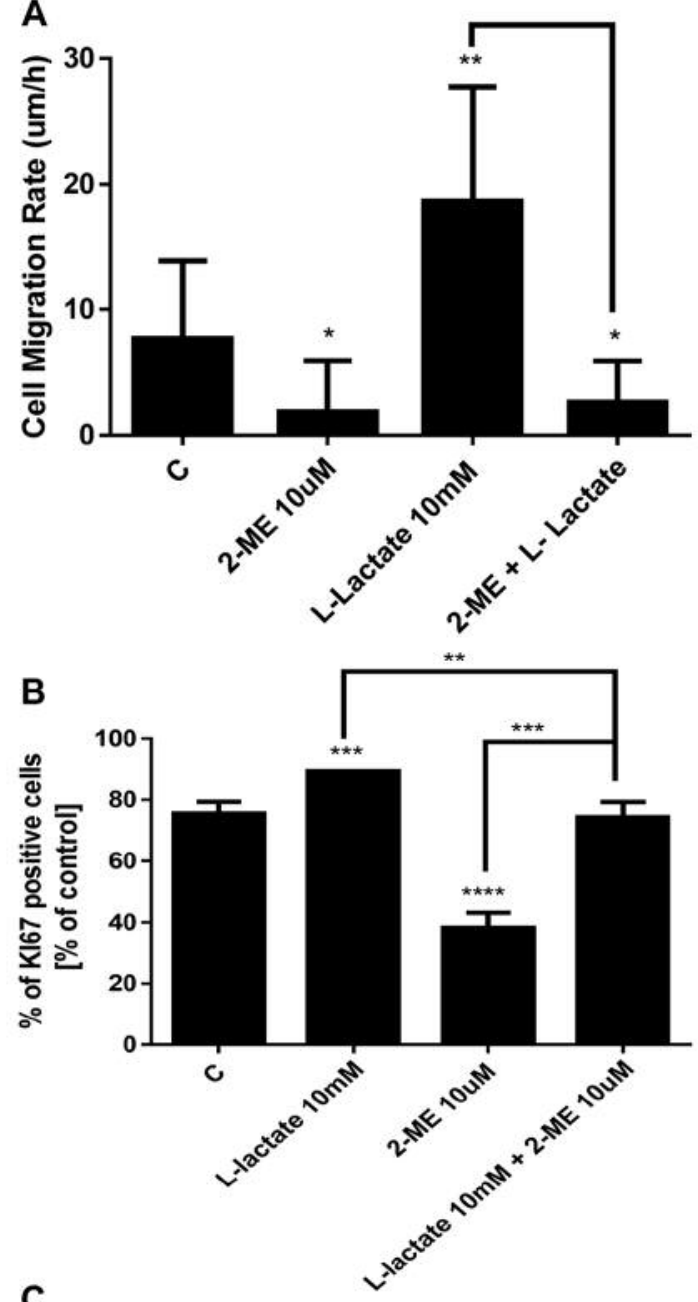

C

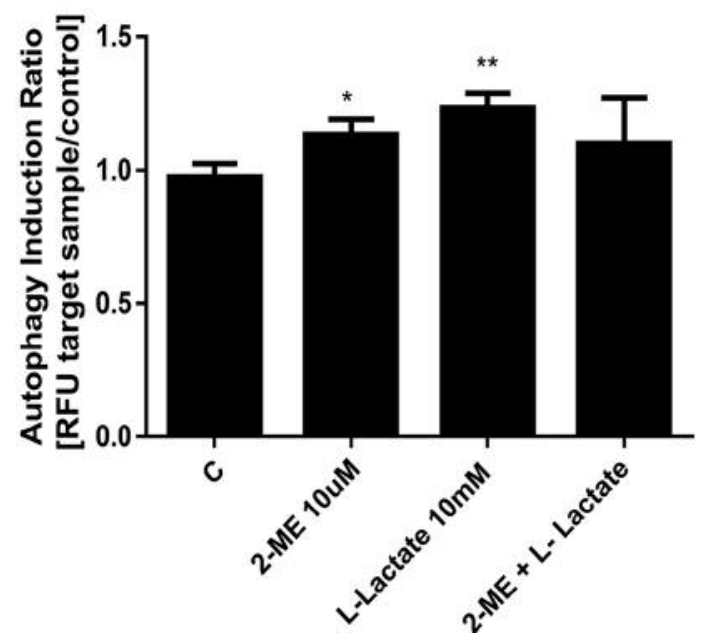

Figure 5. Impact of 2-ME and L-lactate separately or in combination on the migratory potential of osteosarcoma cells (A), Ki-67-positive cells $(B)$, and the induction of autophagy $(C)$. The values are the means $\pm S E$ of three independent experiments ( $N=6$ replicate cultures). The absence of an error bar denotes a line thickness greater than the error. ${ }^{* *} p<0.001, * * * p<0.0001, * * * * p<0.00001$ versus control cells $(C)$.
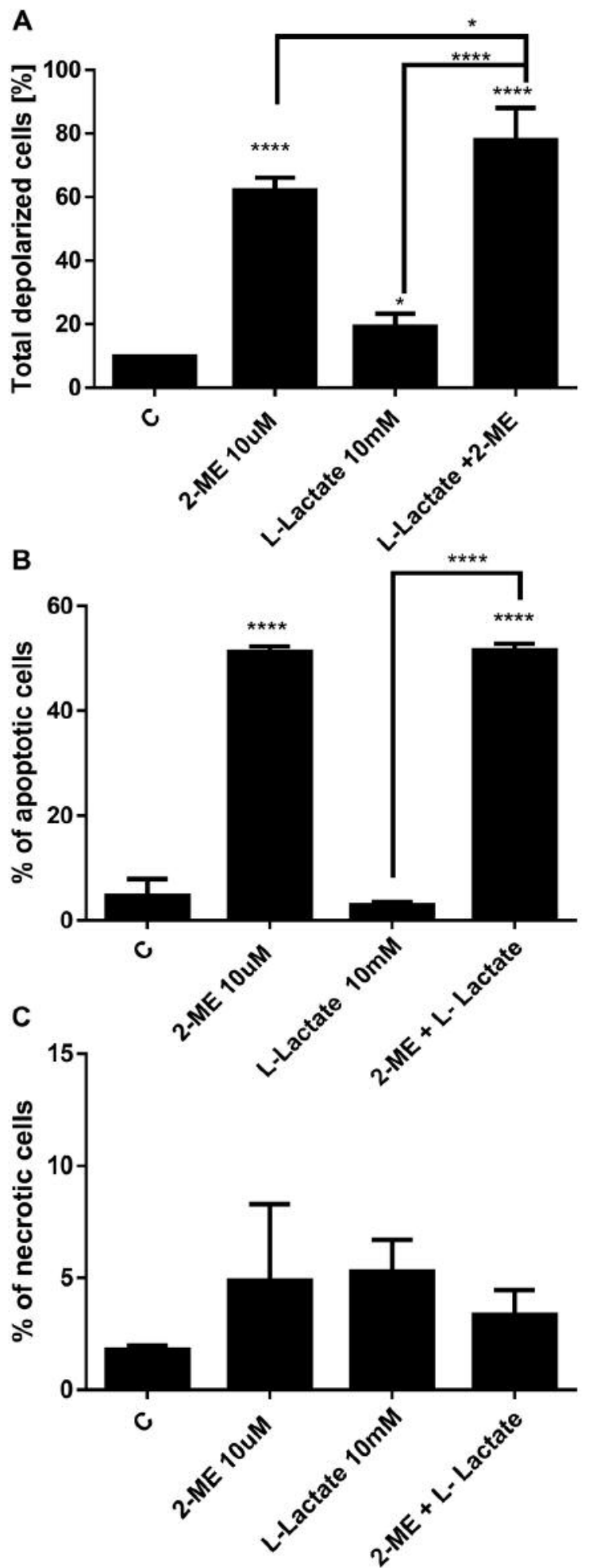

Figure 6. Impact of 2-ME and L-lactate separately or in combination on the mitochondrial membrane depolarization (A), the induction of cell death $(B, C)$. The values are the means \pm SE of three independent experiments ( $N=6$ replicate cultures). The absence of an error bar denotes a line thickness greater than the error. **p<0.001, $* * * p<0.0001, * * * * p<0.00001$ versus control cells $(C)$. 
Impact of treatment with 2-ME and/or L-lactate on the induction of cell death. Based on the molecular crosstalk between the induction of autophagy and induction of cell death by 2-ME (34), the data were then compared with the induction of cell death. Consistent with previous studies (18), $10 \mu \mathrm{M} 2-\mathrm{ME}$ increased the number of apoptotic cells up to $51 \%$ compared with the control cells (4.7\%) (Figure 6B). A 48-h treatment with $10 \mathrm{mM}$ L-lactate did not affect apoptosis in the osteosarcoma cells. Importantly, a 24-h pretreatment and continued treatment of the cells with L-lactate did not affect the pro-apoptotic potential of 2-ME (Figure 5B). We did not observe any impact of the agents used separately or in combination on the induction of necrosis (Figure 6C).

\section{Discussion}

Mitochondrial function plays an important role in carcinogenesis and cancer dell death (35). In early studies, cancer cells were thought to metabolize glucose through aerobic glycolysis due to impaired mitochondrial function according to the Warburg theory (36). According to the Warburg effect, cancer cells convert glucose to lactic acid, even in the presence of oxygen. This results in lactate production as an end product of glycolysis. Currently, there is evidence that metabolic symbiosis between hypoxic and aerobic regions exists throughout the cancer microenvironment (37). Hypoxic cancer cells or cancerassociated fibroblasts produce lactate that is taken up by aerobic cells and fuels tumor growth in an effect termed the 'reversed Warburg effect' (1-3). This effect has especially been observed in breast cancer cells and osteosarcoma cells (1-3).

Only a few reports have considered the effect of 2-ME on mitochondrial function and the mitochondrial apoptotic pathway $(18,21,38-41)$. An anticancer mechanism of 2-ME is associated with the induction of mitochondrial oxidative stress resulting in the induction of the mitochondrial apoptotic pathway in cancer cells $(38,42)$. It was previously demonstrated that 2-ME decreased mitochondrial membrane potential due to generation of nitro-oxidative stress leading to cancer cell death (17-21, 43). However, 2-ME also works as an inhibitor of mitochondrial respiration by inhibiting Complex I (39-41). Importantly, 2-ME-dependent disruption of Complex I was proposed as an alternative mechanism for its proapoptotic effects (39-41). Interestingly, though 2-ME is believed to be nontoxic towards normal cells (44), mitochondrial dysfunction induced by 2-ME was also observed in healthy cells e.g. normal lymphocytes or human embryonic kidney 293 cell line $(41,45)$.

Bonucelli and coworkers demonstrated that L-lactate may play a causative role in breast cancer metastasis (2). Moreover, they observed an association between the altered levels of L-lactate and ketones as the end products of glycolysis in diabetic patients in whom there is an increased incidence of cancer development (2). L-lactate was demonstrated to increase mitochondrial biogenesis and oxidative phosphorylation, which facilitate the migration of cancer cells $(1,2)$. Consistent with these observations, our results confirmed that treatment with $10 \mathrm{mM}$ L-lactate increased the proliferation and migration of osteosarcoma 143B cells. Importantly, the pro-migratory and proproliferative effects of L-lactate were reversed by treatment with a pharmacological concentration of 2-ME. The antimigratory potential of 2-ME has previously been demonstrated in various experimental models $(17,23,24)$. Herein, for the first time, we demonstrated the antagonistic effect between 2-ME and L-lactate. Importantly, 2-ME was able to reverse the pro-proliferative and pro-migratory effects in L-lactate-activated osteosarcoma cells. We demonstrated that the anti-proliferative effect of 2-ME is directly associated with decreases in the expression of $\mathrm{Ki}-67$, which is an important prognostic marker in osteosarcoma (31). An increased level of Ki-67 directly correlates with aggressiveness of tumors and their responses to chemotherapy $(31,46)$. We determined that 2-ME may affect Ki-67 expression in osteosarcoma cells. It has been demonstrated that 2-ME has no antitumor effects on human endometrial carcinoma, in which it did not affect Ki-67 expression (47) whereas 2-ME decreases Ki-67 expression in breast cancer and hepatocellular carcinoma $(48,49)$. Moreover, we demonstrated that treatment with L-lactate results in an increased expression of Ki-67. Previously, the expression of Ki-67 was positively correlated with activity of lactate dehydrogenase $(50,51)$, but not directly correlated with level of L-lactate. Importantly, treatment with 2-ME reversed the L-lactate-induced increase in the expression of Ki-67. The decreased expression of Ki-67 that was induced by 2-ME was directly associated with the decreased mitochondrial membrane potential and induction of apoptosis in osteosarcoma cells. The induction of cell death and tumor growth inhibition that are associated with the abrogated expression of Ki-67 was previously demonstrated (52). The expression of Ki-67 was correlated with the level of LC3, a marker of autophagy (53). Autophagy, for which the formation of double-membrane bound organelles known as autophagosomes is a hallmark, is a lysosome-dependent pathway for protein degradation. Autophagy delivers cytoplasmic material and organelles to the lysosomes for degradation (54). The role of autophagy in carcinogenesis is context-dependent. It was demonstrated that the induction of autophagy is associated with DNA damage (55-57). Autophagy has been shown to regulate some of the DNA repair proteins after DNA damage (55-57). One the other hand, some evidence has demonstrated that some DNA repair molecular have a crucial role in the initiation of autophagy $(58,59)$. The role of oxidative and nitrosative stress in 
autophagy has also been widely discussed (58). In our previous studies, we determined that one of anticancer mechanisms of action of 2-ME is the induction of double- and single-strand breaks due to nuclear hijacking of neuronal nitric oxide synthase $(18,19)$. 2-ME was also shown to induce the DNA damage response pathway (19). Moreover, it was suggested that a malfunction of the DNA damage repair system may result in chemoresistance of cancer cells to 2-ME and further progression of the cancer (19). Herein, we observed that the induction of autophagy by 2-ME was strictly correlated with the inhibition of proliferation and migration and the induction of apoptosis in osteosarcoma cells. The correlation of the induction of autophagy by 2-ME with the induction of cell death has previously been demonstrated in various experimental models including osteosarcoma cells $(60,61)$. Moreover, it has been suggested the molecular crosstalk between 2-ME-induced apoptosis and autophagy is associated with its impact on microtubule integrity in cervical adenocarcinoma cells (62). On the other hand, the inhibition of autophagy increased the anticancer potential of 2-ME in chondrosarcoma cells (63). Thus, autophagy could play a dual role in cancer by facilitating either cell death or cell survival. Autophagy is considered to be a tumor-suppressing mechanism in early-stage carcinogenesis and may mediate the therapeutic effect of anticancer agents $(54,55)$. However, autophagy may also act as a pro-survival mechanism to protect cancer cells from various forms of cellular stress (64). Indeed, the inhibition of autophagy was demonstrated to sensitize osteosarcoma cells to chemotherapeutic agents (64). In cancer therapy, adaptive autophagy in cancer cells sustains tumor growth and survival in the face of the toxicity of cancer therapy. We also determined that the L-lactate-induced autophagy in osteosarcoma cells was correlated with its pro-proliferative and pro-migratory effects, whereas the combined treatment with L-lactate and 2-ME resulted in decreased autophagy. This suggested that the autophagy induced by L-lactate leads to resistance of cancer cells to chemotherapy. Importantly, we also observed that the induction of apoptosis was comparable in the cells treated with 2-ME, or the combination of 2-ME and L-lactate.

\section{Conclusion}

All obtained results confirmed that 2-ME effectively induced tumor cell death, but also acted on the tumor microenvironment. We have demonstrated that 2-ME is an efficient anticancer agent in osteosarcoma cells that underwent L-lactate-induced metabolic reprogramming. Due to the obtained data we suggest that L-lactate is not only an intermediate metabolite but also a signaling molecule. Notably, the level of L-lactate may be a marker of the efficiency of anticancer therapies. High Lactate levels are strictly associated with a poor prognosis and increased metastatic potential of the tumors $(6,7,12)$. The poor prognosis associated with an increased level of L-lactate may be strictly associated with its impact on pro-angiogenetic factors and the induction of mitochondrial biogenesis as well as a direct impact on cancer cell migration and proliferation (1-3). Thus, the level of L-lactate may serve as a marker of the efficiency of anticancer therapies. Moreover, regulation of L-lactate level in the tumor microenvironment seems to be a new tool in the arsenal of weapons against cancer.

We are currently evaluating a plausible role for 2-ME in regulation of the mitochondrial biogenesis pathway. Undoubtedly, the role of 2-ME in regulation of bioenergetics and mitochondrial function is very interesting and remains to be elucidated.

\section{Funding}

The studies and manuscript publication were supported by the Iuventus Plus Programme from of the Polish Ministry of Science and Higher Education No IP 2015022074.

\section{Conflicts of Interest}

The Authors declare no conflicts of interest.

\section{Acknowledgements}

The Authors thank Merck and especially Dr. Barbara Piotrowska for providing the Muse Cell Analyzer for the experiments and for her helpful advice.

\section{References}

1. Bonuccelli G, Avnet S, Grisendi G, Salerno M, Granchi D, Dominici M, Kusuzaki K and Baldini N: Role of mesenchymal stem cells in osteosarcoma and metabolic reprogramming of tumor cells. Oncotarget 15(17): 7575-7588, 2014.

2 Bonuccelli G, Tsirigos A, Whitaker-Menezes D, Pavlides S, Pestell RG, Chiavarina B, Frank PG, Flomenberg N, Howell A, Martinez-Outschoorn UE, Sotgia F and Lisanti MP: Ketones and lactate "fuel" tumor growth and metastasis: Evidence that epithelial cancer cells use oxidative mitochondrial metabolism. Cell Cycle 9(17): 3506-3514, 2010.

3 Sotgia F, Martinez-Outschoorn UE and Lisanti MP: The reverse Warburg effect in osteosarcoma. Oncotarget 5(18): 7982-7983, 2014.

4 Semenza GL: Tumor metabolism: cancer cells give and take lactate. J Clin Invest 118(12): 3835-3837, 2008.

5 Goodwin ML, Gladden LB, Nijsten MW and Jones KB: Lactate and cancer: revisiting the Warburg effect in an era of lactate shuttling. Front Nutr 1: 27, 2015.

6 Brizel DM, Schroeder T, Scher RL, Walenta S, Clough RW, Dewhirst MW and Mueller-Klieser W: Elevated tumor lactate concentrations predict for an increased risk of metastases in head-and-neck cancer. Int J Radiat Oncol Biol Phys 51(2): 349$353,2001$. 
7 Cori CF and Cori HT: The carbohydrate metabolism of tumors II. Changes in the sugar, lactic acid, and $\mathrm{CO}_{2}$-combioning power of blood passing through a tumor. J Biol Chem 65: 397-405, 1925.

8 Warburg $\mathrm{O}$, Winf $\mathrm{F}$ and Negelein E: The metabolism of tumors in the body. J Gen Physiol 8: 519-530, 1927.

9 Walenta S, Salameh A, Lyng H, Evensen JF, Mitze M, Rofstad EK and Mueller-Klieser W: Correlation of high lactate levels in head and neck tumors with incidence of metastasis. Am J Pathol 150(2): 409-415, 1997.

10 Zhou W, Liotta LA and Petricoin EF: The Warburg effect and mass spectrometry-based proteomic analysis. Cancer Genomics Proteomics 14(4): 211-218, 2017.

11 Zhou W, Liotta LA and Petricoin EF: Cancer metabolism: what we can learn from proteomic analysis by mass spectrometry. Cancer Genomics Proteomics 9(6): 373-381, 2012.

12 Romero-Garcia S, Moreno-Altamirano MM, Prado-Garcia H and Sánchez-García FJ: Lactate contribution to the tumor microenvironment: mechanisms, effects on immune cells and therapeutic relevance. Front Immunol 7: 52, 2016.

13 Vassiliou AG, Mastora Z, Jahaj E, Koutsoukou A, Orfanos SE and Kotanidou A: Does serum lactate combined with soluble endothelial selectins at ICU admission predict sepsis development? In Vivo 29(2): 305-308, 2015.

14 Flomenberg N, Witkiewicz AK, Frank PG, Casimiro MC, Wang C, Fortina P, Addya S, Pestell RG, Martinez-Outschoorn UE, Sotgia F and Lisanti MP: The reverse Warburg effect: aerobic glycolysis in cancer associated fibroblasts and the tumor stroma. Cell Cycle 8(23): 3984-4001, 2009.

15 Porporato PE, Dhup S, Dadhich RK, Copetti T and Sonveaux P. Anticancer targets in the glycolytic metabolism of tumors: a comprehensive review. Front Pharmacol 2: 49, 2011.

16 Romero-Garcia S, Lopez-Gonzalez JS, Báez-Viveros JL, Aguilar-Cazares D and Prado-Garcia H. Tumor cell metabolism: an integral view. Cancer Biol Ther 12(11): 939-948, 2011.

17 Gorska-Ponikowska M, Perricone U, Kuban-Jankowska A, Lo Bosco $\mathrm{G}$ and Barone G: 2-methoxyestradiol impacts on amino acids-mediated metabolic reprogramming in osteosarcoma cells by interaction with NMDA receptor. J Cell Physiol 232(11): 3030-3049, 2017.

18 Gorska M, Wyszkowska RM, Kuban-Jankowska A and Wozniak M: Impact of Apparent Antagonism of estrogen receptor $\beta$ by fulvestrant on anticancer activity of 2-methoxyestradiol. Anticancer Res 36(5): 2217-2226, 2016.

19 Gorska M, Kuban-Jankowska A, Zmijewski M, Marino Gammazza A, Cappello F, Wnuk M, Gorzynik M, Rzeszutek I, Daca A, Lewinska A and Wozniak M: DNA strand breaks induced by nuclear hijacking of neuronal NOS as an anti-cancer effect of 2methoxyestradiol. Oncotarget 6(17): 15449-15463, 2015.

20 Gorska M, Kuban-Jankowska A, Zmijewski MA, Gorzynik M, Szkatula $M$ and Wozniak M: Neuronal nitric oxide synthase induction in the antitumorigenic and neurotoxic effects of 2methoxyestradiol. Molecules 28;19(9): 13267-13281, 2014.

21 Gorska M, Kuban-Jankowska A, Milczarek R and Wozniak M: Nitro-oxidative stress is involved in anticancer activity of $17 \beta$ estradiol derivative in neuroblastoma cells. Anticancer Res 36(4): 1693-1698, 2016.

22 Kumar BS, Raghuvanshi DS, Hasanain M, Alam S, Sarkar J, Mitra K, Khan F and Negi AS: Recent advances in chemistry and pharmacology of 2-methoxyestradiol: An anticancer investigational drug. Steroids 110: 9-34, 2016.
23 Wu SL, Li UJ, Liao K, Shi L, Zhang N, Liu S, Hu YY, Li SL and Wang Y: 2-methoxyestradiol inhibits the proliferation and migration and reduces the radioresistance of nasopharyngeal carcinoma CNE-2 stem cells via NF-kB/HIF-1 signaling pathway inactivation and EMT reversal. Oncol Rep 37(2): 793-802, 2016.

24 Sattler M, Quinnan LR, Pride YB, Gramlich JL, Chu SC, Even GC, Kraeft S, Chen LB and Salgia R: 2-methoxyestradiol alters cell motility, migration, and adhesion. Blood 102: 289-296, 2003.

25 Fotopoulou C, Baumunk D, Schmidt SC and Schumacher G: Additive growth inhibition after combined treatment of 2methoxyestradiol and conventional chemotherapeutic agents in human pancreatic cancer cells. Anticancer Res 30(11): 4619-4624, 2011.

26 Foster PA, Newman SP, Leese MP, Bernetiere S, Diolez C, Camara J, Hacher B, Baronnet MM, Ali T, Potter BV, Reed MJ and Purohit A: A new micronized formulation of 2methoxyestradiol-bis-sulfamate (STX140) is therapeutically potent against breast cancer. Anticancer Res 28(2A): 577-581, 2008.

$27 \mathrm{Li} \mathrm{L}$, Heldin NE, Grawé J, Ulmsten U and Fu X: Induction of apoptosis or necrosis in human endometrial carcinoma cells by 2-methoxyestradiol. Anticancer Res 24(6): 3983-3990, 2004.

$28 \mathrm{Li} \mathrm{L,} \mathrm{Bu} \mathrm{S,} \mathrm{Bäckström} \mathrm{T,} \mathrm{Landström} \mathrm{M,} \mathrm{Ulmsten} \mathrm{U} \mathrm{and} \mathrm{Fu} \mathrm{X:}$ Induction of apoptosis and $\mathrm{G}_{2} / \mathrm{M}$ arrest by 2-methoxyestradiol in human cervical cancer HeLaS3 cells. Anticancer Res 24(2B): 873880, 2004.

29 Banerjeei SK, Zoubine MN, Sarkar DK, Weston AP, Shah JH and Campbell DR: 2-methoxyestradiol blocks estrogen-induced rat pituitary tumor growth and tumor angiogenesis: possible role of vascular endothelial growth factor. Anticancer Res 20(4): 26412645,2000 .

30 Fujii H, Honoki K, Tsujiuchi T, Kido A, Yoshitani K and Takakura Y: Growth inhibition and induction of apoptosis by 2methoxyestradiol in rat osteosarcoma and malignant fibrous histiocytoma cell lines. In Vivo 22(1): 21-25, 2008.

31 Scotlandi K, Serra M, Manara MC, Maurici D, Benini S, Nini G, Campanacci M and Baldini N: Clinical relevance of Ki-67 expression in bone tumors. Cancer 75(3): 806-814, 1995.

32 Robl B, Pauli C, Botter SM, Bode-Lesniewska B and Fuchs B: Prognostic value of tumor suppressors in osteosarcoma before and after neoadjuvant chemotherapy. BMC Cancer 15: 379, 2015.

33 Yoshioka A, Miyata H, Doki Y, Yamasaki M, Sohma I, Gotoh K, Takiguchi S, Fujiwara Y, Uchiyama Y and Monden M: LC3, an autophagosome marker, is highly expressed in gastrointestinal cancers. Int J Oncol 33(3): 461-468, 2008.

34 Theron AE, Nolte EM, Lafanechère L and Joubert AM: Molecular crosstalk between apoptosis and autophagy induced by a novel 2methoxyestradiol analogue in cervical adenocarcinoma cells. Cancer Cell Int 13(1): 87, 2013.

35 Tanaka T, Kobunai T, Yamamoto Y, Murono K, Otani K, Yasuda K, Nishikawa T, Kiyomatsu T, Kawai K, Hata K, Nozawa H, Ishihara $\mathrm{S}$ and Watanabe T: Increased copy number variation of mtDNA in an array-based digital PCR assay predicts ulcerative colitis-associated colorectal cancer. In Vivo 31(4): 713-718, 2017.

36 Slobodan D: Warburg effect - a consequence or the cause of carcinogenesis? J Cancer 7(7): 817-822, 2016.

37 Sonveaux P, Végran F, Schroeder T, Wergin MC, Verrax J, Rabbani ZN, De Saedeleer CJ, Kennedy KM, Diepart C, Jordan BF, Kelley MJ, Gallez B, Wahl ML, Feron O and Dewhirst MW: Targeting lactate-fueled respiration selectively kills hypoxic tumor cells in mice. J Clin Invest 118(12): 3930-3942, 2008. 
38 Lee ST, Lee JY, Han CR, Kim YH, Jun do Y, Taub D and Kim YH: Dependency of 2-methoxyestradiol-induced mitochondrial apoptosis on mitotic spindle network impairment and prometa-phase arrest in human Jurkat T cells. Biochem Pharmacol 94(4): 257-269, 2015.

39 Felty Q and Roy D: Estrogen, mitochondria, and growth of cancer and non-cancer cells. J Carcinog 4(1): 1, 2005.

40 Chua YS, Chua YL and Hagen T: Structure activity analysis of 2-methoxyestradiol analogues reveals targeting of microtubules as the major mechanism of antiproliferative and proapoptotic activity. Mol Cancer Ther 9(1): 224-235, 2010.

41 Hagen T, D'Amico G, Quintero M, Palacios-Callender M, Hollis V, Lam $F$ and Moncada S: Inhibition of mitochondrial respiration by the anticancer agent 2-methoxyestradiol. Biochem Biophys Res Commun 322(3): 923-929, 2004.

42 Ting CM, Lee YM, Wong CK, Wong AS, Lung HL, Lung ML, Lo KW, Wong RN and Mak NK: 2-Methoxyestradiol induces endoreduplication through the induction of mitochondrial oxidative stress and the activation of MAPK signaling pathways. Biochem Pharmacol 79(6): 825-841, 2010.

43 Chang I, Majid S, Saini S, Zaman MS, Yamamura S, Chiyomaru T, Shahryari V, Fukuhara S, Deng G, Dahiya R and Tanaka Y: Hrk mediates 2-methoxyestradiol-induced mitochondrial apoptotic signaling in prostate cancer cells. Mol Cancer Ther 12(6): 10491059, 2013.

44 Gorska M, Kuban-Jankowska A, Slawek J and Wozniak M: New insight into 2-methoxyestradiol- a possible physiological link between neurodegeneration and cancer cell death. Curr Med Chem 23(15): 1513-1527, 2016.

45 Georgieva E, Zhelev Z, Aoki I, Bakalova R and Higashi T: Detection of redox imbalance in normal lymphocytes with induced mitochondrial dysfunction - EPR study. Anticancer Res 36(10): 5273-5279, 2016.

46 Jong R, Davis AM, Mendes MG, Wunder JS, Bell RS and Kandel R: Proliferative activity (Ki-67 expression) and outcome in high grade osteosarcoma: A study of 27 cases. Sarcoma 4(12): 47-55, 2000

47 Li L, Yu F, Wu X, Cheng J, Ulmsten U and Fu X: Effects of 2methoxyestradiol on endometrial carcinoma xenografts. J Cancer Res Clin Oncol 133(5): 315-320, 2007.

48 Du B, Wang SY, Shi XF, Zhang CF and Zhang ZZ: The effect of 2-methoxyestradiol liposome on growth inhibition, angiogenesis and expression of VEGF and Ki-67 in mice bearing H22 hepatocellular carcinoma. Tumori 97(5): 660-665, 2011.

49 Azab SS, Salama SA, Hassan MH, Khalifa AE, El-Demerdash E, Fouad H, Al-Hendy A and Abdel-Naim AB: 2-methoxyestradiol reverses doxorubicin resistance in human breast tumor xenograft. Cancer Chemother Pharmacol 62(5): 893-902, 2008.

50 Himani B, Meera S, Abhimanyu S and Usha R: Ki-67 Immunostaining and its correlation with microvessel density in patients with mutiple myeloma. Asian Pac J Cancer Prev 17(5): 2559-2564, 2016.

51 Alexandrakis MG, Passam FH, Kyriakou DS, Dambaki K, Niniraki $M$ and Stathopoulos E: Ki-67 proliferation index: correlation with prognostic parameters and outcome in multiple myeloma. Am J Clin Oncol 27(1): 8-13, 2004.

52 Kausch I, Jiang H, Ewerdwalbesloh N, Doehn C, Krüger S, Sczakiel G and Jocham D: Inhibition of $\mathrm{Ki}-67$ in a renal cell carcinoma severe combined immunodeficiency disease mouse model is associated with induction of apoptosis and tumour growth inhibition. BJU Int 95(3): 416-420, 2005.
$53 \mathrm{Wu}$ WK, Coffelt SB, Cho CH, Wang XJ, Lee CW, Chan FK, Yu $\mathrm{J}$ and Sung JJ: The autophagic paradox in cancer therapy. Oncogene 31(8): 939-953, 2012.

54 Eskelinen EL and Saftig P: Autophagy: a lysosomal degradation pathway with a central role in health and disease. Biochim Biophys Acta 1793(4): 664-7344, 2009.

55 Zhang D, Tang B, Xie X, Xiao XF, Yang SM and Zhang JW: The interplay between DNA repair and autophagy in cancer therapy. Cancer Biol Ther 16(7): 1005-1013, 2015.

56 Eliopoulos AG, Havaki S and Gorgoulis VG: DNA damage response and autophagy: a meaningful partnership. Front Genet 7: 204, 2016.

57 Eapen VV, Waterman DP, Bernard A, Schiffmann N, Sayas E, Kamber R, Lemos B, Memisoglu G, Ang J, Mazella A, Chuartzman SG, Loewith RJ, Schuldiner M, Denic V, Klionsky DJ and Haber JE: A pathway of targeted autophagy is induced by DNA damage in budding yeast. Proc Natl Acad Sci USA 114(7): E1158-E1167, 2017.

58 Filomeni G, De Zio D and Cecconi F: Oxidative stress and autophagy: the clash between damage and metabolic needs. Cell Death Differ 22(3): 377-388, 2015.

59 Eskelinen EL and Saftig P: Autophagy: a lysosomal degradation pathway with a central role in health and disease. Biochim Biophys Acta 1793(4): 664-673, 2009.

60 Bravo D, Shogren KL, Zuo D, Wagner ER, Sarkar G, Yaszemski MJ and Maran A: 2-methoxyestradiol-mediated Induction of Frzb contributes to cell death and autophagy in MG63 osteosarcoma cells. J Cell Biochem 118(6): 1497-1504, 2017.

61 Visagie $\mathrm{MH}$ and Joubert AM: 2-methoxyestradiol-bissulphamate refrains from inducing apoptosis and autophagy in a non-tumorigenic breast cell line Cancer Cell Int 12(1): 37, 2012.

62 Theron AE1, Nolte EM, Lafanechère L and Joubert AM: Molecular crosstalk between apoptosis and autophagy induced by a novel 2methoxyestradiol analogue in cervical adenocarcinoma cells. Cancer Cell Int 13(1): 87, 2013.

63 Reumann S, Shogren KL, Yaszemski MJ and Maran A: Inhibition of autophagy increases 2-methoxyestradiol-induced cytotoxicity in SW1353 chondrosarcoma cells. J Cell Biochem 117(3): 751-759, 2016.

64 Shimizu T, Sugihara E, Yamaguchi-Iwai S, Tamaki S, Koyama Y, Kamel W, Ueki A, Ishikawa T, Chiyoda T, Osuka S, Onishi N, Ikeda H, Kamei J8, Matsuo K, Fukuchi Y, Nagai T, Toguchida J, Toyama Y, Muto A and Saya H: IGF2 preserves osteosarcoma cell survival by creating an autophagic state of dormancy that protects cells against chemotherapeutic stress. Cancer Res 74(22): 6531-6541, 2014.
Received August 15, 2017

Revised October 5, 2017

Accepted October 12, 2017 